\title{
Stress response of farmed European abalone reveals rapid domestication process in absence of intentional selection
}

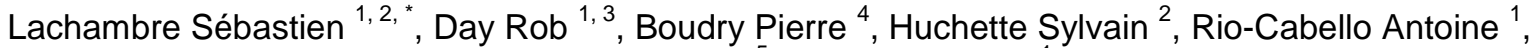 \\ Fustec Tirnothée ${ }^{5}$, Roussel Sabine ${ }^{1}$
}

${ }^{1}$ UBO CNRS IRD Ifremer, Inst Univ Europeen de la Mer, Technopole Brest Iroise, LEMAR,UMR 6539, F-29280 Plouzane, France.

${ }^{2}$ France Haliotis, F-29880 Plouguerneau, France.

${ }^{3}$ Univ Melbourne, Sch Biosci, Parkville, Vic 3010, Australia.

${ }^{4}$ UBO CNRS IRD Ifremer, UMR LEMAR 6539, IFREMER, Ctr Bretagne, F-29280 Plouzane, France.

${ }^{5}$ Inst Super Agr, 48 Blvd Vauban, F-59046 Lille, France.

* Corresponding author : Sébastien Lachambre, email address : sebastien.lachambre@laposte.net

\begin{abstract}
:
Farming, and thus the domestication of Haliotis tuberculata, began recently. We compared the responses of unselected farmed and wild abalone to stressors that occur on farms. The aim was to determine if the farm environment had induced differences in the behavioural or physiological performances of the abalone. Thirty hatchery-born 3.5 year-old abalone and thirty wild ones were reared under standard farm conditions for 6 months and characterised for 19 traits related to growth, survival, behaviour and immunology. Behavioural and immunological responses to stressors differed between the two stocks. Farmed abalone retracted and swivelled less in reaction to a finger contact. Phagocytosis efficiency was reduced by shaking in abalone from both origins, but the farmed stock returned to the basal level after the recovery week, while wild abalone did not, and a rise of total haemocyte count after shaking and its return to a basal level after one week was only observed for the farmed stock. This indicates that both behaviour and immune responses following a stress have been affected by the farming practices. This suggests that a domestication process has already been initiated in the farmed stock. Our results may also be important for the success of any population enhancement based on hatchery-produced abalone as they raise the question of the capacity of abalone with a farmed origin to be adapted to the wild environment.
\end{abstract}




\section{Highlights}

- Domestication effect on the European abalone Haliotis tuberculata biology. $>$ The ethology approach provides useful tools to characterize wild and farmed abalone. Foot contraction and righting latency are indicators of growth and survival after stress procedure.

Keywords: Abalone aquaculture, Domestication syndrome, Behavioural adaptation, Responses to stress, Immune response, Farm stressors

\section{Abbreviations}

ANOVA analysis of variance

PCA principle component analysis

SEM standard error to the mean

Df degree of freedom

NS non significant 


\section{Introduction}

Worldwide, farmed abalone stocks are in the early stages of their domestication process (Elliott, 2000). At the beginning of a domestication process, stocks may acquire specific traits to become more adapted to their captive environment as a result of the stressors or specific conditions in the farm environment (Lorenzen et al., 2012). As farming of these species has begun only recently, the study of behavioural and physiological responses to common stressors on farms may be useful both to improve the husbandry system and to study the domestication process.

Abalone are herbivorous marine gastropods that occur naturally in coastal waters of all continents. The European abalone Haliotis tuberculata is found on sheltered to exposed rocky shores between the intertidal and 10 meters depth, where it leads a cryptic life (Forster, 1962). Haliotis tuberculata is exclusively nocturnal in the wild. It was reported to move less than $10 \%$ of its time during the spring at $18^{\circ} \mathrm{C}$ (Allen et al., 2006; Cenni et al., 2009). Like most abalone species, Haliotis tuberculata is highly sensitive to environmental changes (Cenni et al., 2010). Farm stressors, like high temperature or high density (Huchette et al., 2003; Hooper et al., 2014a), manipulations (Hooper et al., 2011a), shaking (Malham et al., 2003), high ammonia or low oxygen saturation (Cheng et al., 2004c) and air exposure (Ragg and Watts, 2015) are known to produce higher disease susceptibilities and subsequent mortalities or reduced growth. Abalone that can tolerate these rearing stressors are more suitable for producers (Robinson et al., 2013). But multiple stressors may occur in an abalone rearing system and their consequences are often observed after some delay. Thus it is important to observe abalone for a long enough period after the stress application when studying stress responses (Ragg et al., 2000; Ragg and Watts, 2015).

To quantify the degree of fish domestication in aquaculture, a 5-level scale has been proposed (Teletchea and Fontaine, 2014). The level 0 is attributed to species that are only 
harvested by fisheries. 1, 2 and 3 are considered "pre-domestication phase" levels, where the life cycle is not closed in the farm. At level 3, the animals are grown in a farm, but wild animals are used as broodstock to produce larvae. At level 4, the larvae are produced using farm reared broodstock, and unintentional selection can occur progressively across the generations. At level 5, a selective breeding plan involving intentional selection is implemented leading to clear genetic differentiation between wild and farmed population.

For marine species in the pre-domesticate phase, the impact of rearing environment on behaviour and physiology may be higher than for terrestrial species. Indeed most marine species have high phenotypic plasticity and rapid unintentional selection is facilitated by high fecundity and high mortality rates at early stages, imposed by the rearing system in the early phases of production (Taris et al., 2007; Lorenzen et al., 2012). Thus behavioural changes may occur quickly for these species. Indeed, immune and metabolic changes in fish, associated with differential expression of hundreds of genes have been observed after only one generation of domestication (Christie et al., 2016), and interestingly small changes of rearing environment with no intentional selection affect the behaviour differentiation between wild and farmed stock (Straus and Friedman, 2009). In Australia, abalone produced from broodstock selected for a high growth rate over three generations displayed higher mobility than wild specimens (Robinson et al., 2013). A loss of predator avoidance reactions in farm-reared abalone may explain the low survival success of some stock rebuilding or enhancement strategies, where farm-produced juveniles were used (Kojima, 1995). Experiments to investigate the feasibility of abalone enhancement strategies have underlined the importance of understanding their behaviour and ecology in order to maximize the chance of success (Dixon et al., 2006; Hansen and Gosselin, 2013). Predation has been identified as the highest source of mortality in outplanting strategies (Hansen and Gosselin, 2013), and hatchery stock of Haliotis 
kamtchatkana originating from wild broodstock showed an anti-predator behavioural deficit compared to wild stock (Hansen and Gosselin, 2016).

Previous work has shown that behavioural and physiological reactions to stressors are indicators of suboptimal conditions in abalone. For example, a deficit in calcium in the water can induce a reduction in sheltering behaviour (Cenni et al., 2010). Handling stressors like the sampling of an epipodium resulted in increased movement (Robinson et al., 2013). Physiological traits such as immunological parameters can also be used to assess the effect of such stress (Hooper et al., 2007; Ragg and Watts, 2015). In abalone, haemocytes are the main defense cells (Travers, 2008); the density of haemocytes in circulation and their phagocytic activity both vary after a stress. A shaking of fifteen minutes and heat stress both enhance phagocytosis rate, which then returns to the basal level within two days (Malham et al., 2003; Hooper et al., 2014a), and suboptimal rearing conditions or handling procedures induces a decreased phagocytosis rate, which returns to the control level within 5 days (Cheng et al., 2004b; Cheng et al., 2004c; Hooper et al., 2011a). Similarly, the total haemocyte count in samples of haemolymph was increased by shaking and heat stress (Malham et al., 2003; Hooper et al., 2011a; Hooper et al., 2014a), but decreased when the water quality decreased (Cheng et al., 2004a).

Based on this international research in abalone biology, the present study aimed to compare behavioural and physiological responses to farm stressors of farmed abalone (at domestication level 3) and wild European abalone (domestication level 0). Our objective was to assess if the early domestication process may have impacted abalone behaviour and physiology in a farming context. The eventual consequences on growth and mortality were also studied. 


\subsection{Animals}

Farmed adult $H$. tuberculata $(\mathrm{n}=30,70.0 \pm 4.0 \mathrm{~mm}$ total shell length, 3.5 years old $)$ were sampled from 9 sea-based breeding structures of the company France Haliotis $\left(48^{\circ} 36^{\prime} 46 \mathrm{~N}\right.$, 4³3'30W; Plouguerneau, France). Abalone were sampled randomly: an abalone was selected haphazardly, and then the $3^{\text {rd }}$ closest neighbour to this animal was gently detached ('chipped') from the surface and tagged. The animals of the experiment were the third generation bred in the farm, as a result of systematic mating in each generation between wild and farmed broodstock (either males or females were wild broodstock) to prevent any inbreeding. Thus this stock can be considered to be at domestication level 3 (Teletchea and Fontaine, 2014). A professional diver collected wild adults of similar size to the farmed ones $(n=30,70.1 \pm 4.0$ mm total shell length, age unknown) on the same day, near to the sea-based rearing structures, separated from them by at least $100 \mathrm{~m}$ of sandy bottom. We assume that no genetic contamination occurs in this area because the biomass of abalone is low considering wild population and farm abalone are harvested before that they reach complete maturity (Clavier and Richard, 1986). Farm abalone have a green coloration at the apex, as a result of the juveniles feeding on Ulvella. Shells of wild abalone were examined to make sure that they were not escapees from the farm. Individuals of this population can be considered at domestication level 0 at the beginning of the experiment (Teletchea and Fontaine, 2014). Both farmed and wild abalone were inspected when chipped, to ensure there were no cuts on the feet, and placed in bags containing circular black plastic oyster seed collectors as attachment surfaces (diameter: $140 \mathrm{~mm}$ ). Wild abalone were transported to the laboratory in a $100 \mathrm{~L}$ seawater tank in less than one hour, to be held for 3 weeks in experimental tanks, during which time their responses to stressors were measured. Then they were transferred into sea-growing structures for 5 months. 


\subsection{Experimental tanks}

The experimental tanks consisted of two grey, flat, sub-square, epoxy-painted fibreglass tanks $(1.10 \mathrm{~m} \times 1.10 \mathrm{~m} \times 0.20 \mathrm{~m}$, water volume $=100 \mathrm{~L})$ with rough plastic grass strips on the edges

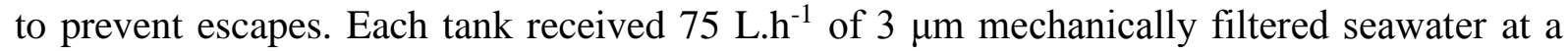
temperature of $10^{\circ} \pm 1^{\circ} \mathrm{C}$ and an aeration system was placed in each tank. Ten pairs of oyster collectors as hides were uniformly distributed along the tank edges. Photoperiod was adjusted to the seasonal rhythm 10:14h (light: $8: 30 \mathrm{~h}$ to $18: 30 \mathrm{~h}$ ). To avoid stressful conditions during light changes, the light was adjusted slowly for 30 minutes during dawn (8:00 to 8:30 h) and dusk (18:30 to 19:00 h) using a dimmer (Gold Star, Besser Elektronik, Italia). Tanks were cleaned twice a week using a hose and the water filters were changed every day. Palmaria palmata, Saccharina latissima, Laminaria digitate and Ulva lactuca, algae that occur on the farm and on the Plouguerneau sea-shore, were placed in 4 plastic boxes in the middle of the tank. All tanks were continuously videotaped with 4 digital cameras (TS-WD6001HPSC, Sygonix Gmbh, Germany), linked to a 24h-recording device (TVVR 40021, Abus, Germany).

\subsection{Experimental stress factors}

Growth, survival and behavioural and immunological traits were measured in the laboratory in three batches, from December to February. For each batch, 10 wild and 10 farmed abalone were carefully chipped with a spatula from their attachment surface, length and weight was measured and abalone were individually marked with a reflective tag and a numbered plastic tag attached with cyanoacrylate glue to their shell (Shepherd, 1988). They were then placed by origin into two experimental tanks.

The laboratory observations (of responses to stressors) were made over three periods, corresponding to three stressors that are regularly experienced by abalone during husbandry procedures: 
- The habituation period (days 1 to 7) corresponded to the period of recovery from the mild stress of transport and handling and living in the lab environment. Previous observations have shown that the stress of chipping and tagging has no impacts on assays of haemocytes after 3 days (Hooper et al., 2011b).

- The high density period (days 8 to 14 ) : 52 additional individuals were added to each tank on day 8 in order to induce a high-density stress (62 abalone. $\left.\mathrm{m}^{-2}\right)$ slightly higher than the densities normally used in the farm. This stress lasted one week, and the extra animals were removed on day 15 .

- The post-acute stress period (days 15 to 21 ): on day 15 , abalone were detached and shaken (three jolts per second of $3 \mathrm{~cm}$ height) with an oyster farm spat screener for 20 min in air, which mimicked the stress experienced by abalone during the screening process to separate sizes on farms (Hooper et al., 2011a). After one hour of emersion and shaking, they were put back into their tank. After the stress, the abalone were left undisturbed until day 21 , when immunological parameters and righting time were measured.

When all batches were completed, the abalone were replaced in a grow-out sea-cage (10 abalone. $\mathrm{m}^{-2}$ ) for 2.5 months (post-stress sea growing period, Figure 1) at low density so that the maximum subsequent growth and survival would be expected. At the end of May (T3), the grow-out sea-cage was brought to the farm. Weight, length, visual gonad index and the survival of each abalone were determined before they were returned to the sea-cages at the normal rearing density (50 abalone. $\mathrm{m}^{-2}$ ) for a summer growth period. In August (T6) after about 6 months of grow-out, they were brought back to the experimental tanks, measured to determine growth and observed for 10 days to measure survival capacity after the handling procedure in summer. This stress involved one hour of emersion due to the carrying of abalone from the sea to the hatchery and chipping to remove the abalone from the sea-cages and place them in the 
experimental tanks (Figure 1).

197

198

199

200

201

202

203

204

205

206

207

\subsection{Growth and Survival}

The variables are listed in Table 1 for reference. Length (L) was measured at T0, T3 and T6 for each batch of abalone and each origin (Table 1). Growth and survival were calculated using the initial measurement times for each batch and period. The first growing period $\left(G_{0-3}\right)$ is related to their ability to recover during and after acute stressors, the second growing period $\left(G_{3-6}\right)$ occurred under the usual farm rearing conditions, although there is also a change between spring and summer between these growth periods.

$$
\begin{aligned}
& G_{0-3}=30 *\left(\mathrm{~L}_{\mathrm{T} 3}-\mathrm{L}_{\mathrm{T} 0}\right) /(\mathrm{ND}) \\
& G_{3-6}=30 *(1) \\
& \left(\mathrm{L}_{\mathrm{T} 6}-\mathrm{L}_{\mathrm{T} 3}\right) /(\mathrm{ND})
\end{aligned}
$$

Where: ND is the number of days between measurements.

Mortalities were recorded over time when abalone were found to be dead in the tanks or by the observation of empty shells in the rearing structures. A 5-level scale (SurvRank- see Table 1) was used for subsequent analysis.

\subsection{Behavioural measurements}

A reactivity test was performed on the last days of both the habituation period and the high density period between 16:30 and 19:00. It involved gently touching the abalone with a finger on the border of the abalone and running the finger clockwise around the abalone in $10 \mathrm{~s}$. Reactions were observed before, during and for $5 \mathrm{~s}$ after touching the abalone.

- At rest, before touching the foot, the retraction of the foot was recorded as Hab.RetractTO for the habituation period and as HighD.RetractTO for the high density period (criteria: $\mathrm{O}$ if retracted, $\mathrm{P}$ if partially relaxed, $\mathrm{N}$ if relaxed). The 
foot was considered retracted when the shell was in contact with the edge or the bottom of the tank.

- While touching the abalone, the protective swivelling movement of the shell was recorded as Hab.SwivellT1 for the habituation period and as HighD.SwivellT1 for the high density period.

- After touching, the contraction of the foot was recorded as Hab.RetractT2 for the habituation period and as HighD.RetractT2 for the high density period.

A righting test was performed on day 21 , the last day of the post-acute stress period, just after the haemolymph sampling procedure described below, in order to have a measure of the energy reserves of the abalone after the 3 weeks of stress and recovery (Baldwin et al., 2007). The righting test was performed after the haemolymph sampling in order to have an unbiased measurement of the haemolymph parameters. Indeed handling can affect haemocyte parameters in less than 5 minutes and for up to 3 days (Malham et al., 2003; Hooper et al., 2011a). Abalone were gently placed on their back in the center of a white 12-L bucket containing $5 \mathrm{~L}$ of sea water at the same temperature as the tanks. The abalone were filmed for 4 min with a camcorder (Sony, HDR-XR155), to measure how long they took to right themselves, using the software VLC media player. The time to right themselves (Righting) was measured from the moment the abalone was placed in the bucket on its back to when it had fully turned over. If an abalone did not turn over in 4 minutes, a 4-min maximum time was recorded.

\subsection{Immunological measurements}

Measures of phagocytosis efficiency and total haemocyte count (THC) were performed on day 15, just before the shaking at the end of the high density period (THCTO, PhagoTo), 30 minutes after the beginning of the shaking $\left(\right.$ THC $_{T 30}$, Phago $\left.{ }_{T 30}\right)$ and 60 minutes after the beginning of 
shaking $\left(\right.$ THC $_{T 60}$, PhagoT60). Final measures of THC and phagocytosis efficiency were also performed $\left(\right.$ THC $_{T e n d}$, PhagoTend $)$ at the end of the experiment, on day 21 . To reduce the direct impact of haemolymph sampling as a stressor, this measurement was performed by a single experienced person and if sampling was done in more than $1 \mathrm{~min}$, the procedure was stopped in order to avoid excessive stress and mortality linked with the sampling.

Following the protocol of Duchemin et al. (2008), haemolymph (less than $0.2 \mathrm{ml}$ per individual) was collected from the pedal sinus for these measurements, using a $1 \mathrm{ml}$ syringe and fine needle. Each abalone was sampled in less than 2 minutes, by the same person. The sample was transferred into a vial and kept on ice. Samples were treated just after collection to avoid aggregation. Haemolymph was used for determining: (1) total haemocyte count (150 $\mu 1)$; (2) phagocytosis efficiency $(50 \mu \mathrm{l})$. Both analyses were performed on a FACS-Calibur flow cytometer (Becton Dickinson, France) equipped with a $488 \mathrm{~nm}$ laser. Cells were counted for 60 s. The immunological parameters were calculated using WinMDI software.

For the THC samples, $150 \mu \mathrm{l}$ of haemolymph was immediately added to $6 \%$ formalin $(100 \mu \mathrm{l})$ and kept at $4{ }^{\circ} \mathrm{C}$ before analysis, when it was diluted into $200 \mu \mathrm{l}$ of filtered and sterile seawater (FSSW) and incubated for $30 \mathrm{~min}$ in dark conditions with SYBR green fluorescent dye (4 $\mu$, Molecular Probes, $10^{-3}$ dilution of the commercial stock solution) before flow cytometry. Results were expressed as number of cells. $\mu \mathrm{L}^{-1}$.

To measure phagocytosis efficiency, a protocol adapted from Travers et al. (2008a) was followed. In summary, $50 \mu \mathrm{l}$ of haemolymph was deposited into a 24 -well plate containing 50 $\mu \mathrm{l}$ of sterile seawater. Haemocytes were allowed to adhere for $15 \mathrm{~min}$ at $18^{\circ} \mathrm{C}$. Then $30 \mu \mathrm{l}$ of fluorescent beads (fluoresbrite YG Microspheres $2.00 \mathrm{~mm}$, Plysciences, 1:100 in distilled water $)$ were added. After $2 \mathrm{~h}$ at $18^{\circ} \mathrm{C}$, supernatants were removed, $100 \mu \mathrm{l}$ of trypsin $\left(2.5 \mathrm{mg} . \mathrm{mL}^{-}\right.$ ${ }^{1}$ in AASH anti-aggregant solution) was added; and the plates were shaken for 10 min to detach the adherent cells. Then $100 \mu \mathrm{l}$ of $6 \%$ formalin was used to fix the cells. Samples were kept at 
$4^{\circ} \mathrm{C}$ before analysis by flow cytometry. The phagocytosis efficiency (Phago) was defined as the percentage of haemocytes that had engulfed three or more beads.

\subsection{Statistical analyses}

Statistical analyses were performed with $\mathrm{R}$ 3.0.3 software. After a verification of the assumptions of variance homogeneity and normal distribution, comparisons of growth measurements between the farmed and wild abalone were done using an ANOVA model with the origin as a fixed effect (wild versus farmed). Differences between the two origins on the qualitative behavioural variables were tested by a Fisher test. For each of the immunological variables, the first analysis was a repeated measure ANOVA to determine whether the timing of the measurement had an effect for each origin. A log transformation of the THC and a logit transformation of the percentage phagocytosis were used (Warton and Hui, 2011). The second step of this analysis was to compare the two origins at each time of measurement using a Kruskal-Wallis test (Day and Quinn, 1989) because the two variables did not satisfy the assumption of variance homogeneity.

A NMDS (non-parametric multi-dimensional scaling) was carried out with the package MASS on R 3.2.2, as a first step in a multi-dimensional analysis of the dataset. The aim of the NMDS was to select variables that discriminated the two groups (data not shown). Based on the ANOVAs of the variables for behaviour and imunology, those variables that were not significantly different between origins were progressively removed from the NMDS analyses, to find a combination of variables that clearly discriminated the origins at a stress level $<0,05$ with $\mathrm{k}=2$. The variable SurvRank was retained in the analyses, to see if there was any relationship between survival and the other variables. The second step was carried out by using the Factominer package to plot two Multi Factorial Analyses (MFA) (Lé et al., 2008). The eight variables identified as discriminant in the NMDS analysis were reduced and scaled before the 
implementation of the two MFA models. The first analysis was focused on the 60 individuals observed in the laboratory period to study the survival process. This model was implemented with 4 quantitative variables (SurvRank, $T H C_{T 60}, T H C_{T e n d}$, PhagoTend) and 1 qualitative variable (Origin). In this dataset $8 \%$ of the data were missing. In order to increase the degrees of freedom and use the information from all the individuals, a regularized iterative imputation was performed on the dataset, using the package missMDA (Josse et al., 2013). Iterative imputation can create false correlation in the dataset (Quinn and Keough, 2002). To reduce this risk, a recommended methodology was followed before the implementation of the analysis (Quinn and Keough, 2002). This imputation was carried out after an optimization step of noise reduction, in order to implement values by iteration independently of the noise and decrease the risk of creating false correlations (Josse et al., 2013).

The second MFA model was built to study the growth of the 21 individuals that survived after 6 months in the experiment, with 5 quantitative variables $\left(G_{0-3}, G_{3-6}, T H C_{T 60}, T H C_{T e n d}\right.$, Phago $_{\text {Tend, }}$ ) and one qualitative variable (Origin). The same imputation process was applied as $3 \%$ of the data were missing.

In the two MFA the quantitative variables were pooled in three groups in order to give the same weight to each group: the Growth $\left(G_{0-3} ; G_{3-6}\right)$, the Survival (SurvRank), and the Immunology

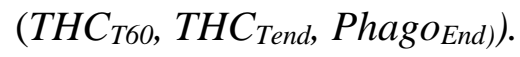




\section{Results}

\subsection{Behavioural traits}

Overall, $62 \%$ of the abalone had a retracted foot before their reactivity test was initiated, and $80 \%$ after touching. No significant differences were observed between the habituation and high density periods for retraction before and after the foot was touched (Table 2). Foot retraction was not significantly different before touching between the farmed and wild abalone (Table 2). After touching however, wild abalone performed more swivelling movements and the foot was more often retracted than in farmed abalone, both after the habituation period and after the high density period (Table 2). No significant difference in the righting time was observed between farmed and wild abalone at the end of the post-acute stress period (Table 2).

\subsection{Immunological traits}

High individual variability was observed for both phagocytosis efficiency and total haemocyte count, with the standard deviation representing respectively $40 \%$ and $50 \%$ of the mean. The shaking stress generated a decrease in phagocytosis efficiency, with a maximum decrease 60 minutes after the end of the shaking period (Figure 2a). After 6 days, the phagocytosis efficiency was back to a value close to the value observed before the stress. The decrease between $\mathrm{T} 0$ and $\mathrm{T} 60$ was significant in abalone from both origins (Figure 2a). THC values were relatively stable for the wild abalone before, 30 and $60 \mathrm{~m}$ after the shaking and 6 days later (around 3000 cells. $\mu \mathrm{L}^{-1}$ ), whereas they rose significantly for the farmed abalone and were at their highest level 60 minutes after the end of the stress period (Increase from 4000 to 5500 cells. $\mu \mathrm{L}^{-1}$ ) (Figure 2b). Five days later, the THC for the farmed abalone had declined significantly (2200 cells. $\left.\mu \mathrm{L}^{-1}\right)$ (Figure 2b). 
For all times of measurement, no significant differences in the phagocytic efficiency were observed between the two origins, although the sample means differed at T60: wild abalone tended to have a lower phagocytosis efficiency than farmed abalone (respectively, 20 vs $24 \%$, $\mathrm{K}=2.8, \mathrm{P}=0.09$ ). The THC values were, in contrast, significantly lower for wild abalone after the density stress before the shaking, and after the shaking stress at T60 compared to the farmed abalone (Figure 2b). At the end of the post-stress period this difference was reversed: wild abalone had significantly higher THC values (Figure $2 b$ ).

\subsection{Survival and growth}

The two origins presented similar mortality patterns, with a major mortality event observed in the first months of rearing after the stress. No difference of survival was observed between the wild and farmed abalone after 6 months of the experiment (Table 3). Almost no growth was observed during the post-stress period, so there was no difference between wild and farmed abalone. However, during the 3-6 month period, farmed abalone grew significantly faster than wild abalone (Table 3). Growth performances just after the stress period and in the later summer period were significantly correlated $(\mathrm{t}=2.68, \mathrm{df}=20, \mathrm{P}=0.01)$.

\section{4 $1^{\text {st }}$ Multivariate analysis: origin, immune parameters, and survival after}

\section{stress}

In the first MFA model, based on 60 individuals, the first two components explained $60 \%$ of the total variance (34\% for the first, $26 \%$ for the second) (Figure 3). The two groups were clearly discriminated by the analysis (Vtest> 2) (Figure 3,1). The most important loadings on the first component were the origin and the immunity parameters (Table 4). This component represents the differential immune responses of the two origins during the laboratory period. The $\boldsymbol{T H C}_{\boldsymbol{T} \boldsymbol{} \boldsymbol{0}}$ and the $\boldsymbol{P h a g o}_{\text {Tend }}$ were associated and opposed to the $\boldsymbol{T H C}_{\text {tend }}$ (Figure 3.2). The most important loading on the second component was the survival rate (Table 4) (Figure 3). No 
immunological parameter had an important loading in this component. This indicates that abalone of the two origins were different from an immunological point of view, but their origin and the immune parameters seemed to be not related to their survival after the stress period (Figure 3).

\section{5 $2^{\text {nd }}$ Multi-variate analysis: origin THC and growth}

In the second MFA model based on 21 individuals still alive after 6 months of experiment, the first two components explained $64 \%$ of the total variance ( $42 \%$ for the first, $22 \%$ for the second) (Figure 4). The two origins were clearly discriminated by the model on the first component (Vtest> 2) (Figure 4, 1 ). The most important loadings on the first component were the origin (Origin), the growth in the summer period $\left(\boldsymbol{G}_{3-6}\right)$ and the THC 60 min after the shaking $\left(\boldsymbol{T H C}_{\boldsymbol{t} \boldsymbol{0} \boldsymbol{0}}\right)$ (Table 4). This component can be interpreted as the differential capacity of the two groups to react to the shaking stress and later growth in the normal rearing conditions (Figure 4,2 ). In the second component, the most important loadings were the THC at the end of the laboratory period ( $\mathrm{THC}_{\boldsymbol{T}}$ end $)$ and growth in the spring period $\left(\boldsymbol{G}_{\mathbf{0 - 3}}\right)$ but this component was not associated with origin. This component may represent the resilience of individuals to the shaking stress in terms of post stress THC response and growth.

(1)
1

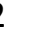

3


The study was designed to assess the potential effects of early domestication on behaviour, physiology, and production traits, by comparing a farmed stock with a wild stock in

a farm environment. We have found that farmed and wild abalone could be discriminated by several different traits related to rearing stressors early in the domestication process.

Firstly, during habituation and in the high-density period, wild abalone retracted their foot more frequently and did more swivelling movements than farmed ones in response to a finger contact. These results are consistent with other observations done in H. kamtschakana (Hansen and Gosselin, 2016). The swivelling shell movements have been described as responses to predator contact (Day et al., 1995; Allen et al., 2006) and heat stress (Hooper et al., 2014a). Two hypotheses can be proposed: either the farmed abalone were less stressed by a contact and did not react to it, or they have partially lost the capacity to react their foot in response to a contact. The testing of these hypotheses is important for any restocking programs for European abalone (Lorenzen et al., 2012) and can explain why outplanted hatchery stocks are subject to high predation mortality (Hansen and Gosselin, 2013). Further studies are required to determine if this result indicates a habituation to this stress or a loss of reflex for farm animals that were raised in an artificial environment, with no predators and frequent handling. These results show that abalone behavioural reactions to stress can be significantly modified by a single cycle of domestication. Such changes have been described in some farmed fish species (Millot et al., 2010). The first generation of hatchery salmon obtained with no intentional selection had a lower fitness in the wild than wild stocks, which highlights that a genetic adaptation to a captive environment can occur in a single generation with deleterious effects in the wild (Christie et al., 2012). This quick adaptation in response to unintentional selection can be explained by a large effective population size (Christie et al., 2012), and a high 
mortality rate in the first production stages in most farmed aquatic species (Taris et al., 2007). Conversely, wild and unselected farmed sea bass populations were reported to present similar reactions to stress (Millot et al., 2010).

In both farmed and wild abalone, $62 \%$ had a retracted foot during the day, before they were disturbed. The normal foot contraction during the day in wild abalone was not modified in the farmed abalone by the early domestication process. Donovan et al. (1999) proposed 2 hypotheses to explain the variation in foot position seen in an abalone population: (1) individuals with a relaxed foot might have lower energy consumption; and (2) individuals with a contracted foot may have higher energy consumption but less chance of being removed by predators. As abalone are nocturnal (Cenni et al., 2009), it would be interesting to perform these observations at night, when the frequency of individuals with retracted feet is expected to be lower (Cenni et al., 2010).

The second set of parameters that discriminated the two stocks were the immunological traits following the acute stress of 20 minutes of shaking coupled with an emersion of one hour. The phagocytosis rate of both stocks decreased after the shaking and had partly recovered by the end of the experiment. This result is not congruent with results reported by Malham et al. (2003) on the same species, but is in accordance with other studies showing that stress induces a reduction of phagocytosis capacity for some time after the stress (Cheng et al., 2004b; Hooper et al., 2014a) on other abalone species. The lowest values of phagocytosis rate were observed 60 minutes after the shaking period and were significantly different from the basal level for both stocks.

After one week of recovery, the phagocytosis rates were still lower than those measured just before the shaking stress for the wild abalone, indicating that wild abalone may need more than one week to completely recover from an acute shaking stress. The farmed stock had returned to 
the basal level, which may indicate a better adaptation to acute farm stressors, probably due to previous exposure to this stressor one or perhaps two times during the rearing process. This result suggests that a single cycle of domestication without intentional selection can alter the dynamic of the stress response, which is a key measure of the animal's robustness and adaptation to the environment (Monget and Le Bail, 2009; Friggens et al., 2010).

The phagocytosis efficiency was similar to the one reported in summer in a previous study H. tuberculata (Travers et al., 2008b). The phagocytosis rate of Haliotis tuberculata observed in our study is also close to that reported in Haliotis diversicolor in Taiwan (Cheng et al., 2004b), but lower than in the Australian hybrid Haliotis laevigata * Haliotis rubra (Hooper et al., 2011a; Hooper et al., 2014b), although there may be some differences due to the methods used. Phagocytosis efficiency at T60 and at the end of the stress procedures was unexpectedly not correlated with the later survival of the studied abalone. It has been proposed that a decrease of phagocytosis efficiency is related to an increase in disease susceptibility (Malham et al., 2003; Cheng et al., 2004a; Hooper et al., 2011a), but eventual subsequent mortality will likely depend on both the physiologic status of an individual and its likelihood to be infected by a pathogen in its environment (Travers, 2008; Lachambre et al., 2017). Pathogens were presumably not abundant during our stress period.

The Total Haemocyte Counts (THC) were measured to follow the immunological status of abalone, but haemocytes are also important in different functions like the carrying of energy reserves (Travers, 2008). In our study, different responses to shaking were observed in the two stocks. The wild abalone always showed lower total THC across all the measurements after the shaking. In contrast, THC in the farmed abalone rose after the shaking and decreased after one the week of recovery. The pattern of response in the farm abalone is consistent with previous observations (Malham et al., 2003). The increased response of farmed abalone may indicate that they were able to react more to the combined acute stress of shaking and emersion; and is 
consistent with what was observed for the phagocytosis efficiency. In further studies, it would be interesting to complete this observation with glucose or glycogen measurement in order to determine if these two response patterns are linked with physiological status or the availability of reserves in individuals. In our study, the differences between farmed and wild stock might be linked with energetic reserves available before the experiment. A farm environment is characterised by a high food availability (Travers, 2008). This hypothesis is consistent with the fact that wild abalone need more time to right themselves (Lachambre et al., 2017).

Our factor analysis showed that THC of individuals 60 minutes after the shaking was positively related with the phagocytosis at the end of the experiment and negatively related to THC at the end of the experiment. Consequently, the THC level observed one hour after the shaking and the depression in phagocytosis after the recovery week may be associated parameters that are part of the same stress reaction. The rise of THC after a stress has been proposed as a positive reaction to stress (Cheng et al., 2002; Cheng et al., 2004c; Travers, 2008). Farmed abalone have been shaken at least once or twice at juvenile age during husbandry rearing, so that their modified reaction may indicate phenotypic plasticity in response to the repeated stress.

The two MFA models show that abalone origin can be clearly differentiated, based on the immunological differences discussed above between the origins. Interestingly, these differences were not associated with significant differences in survival between the two origins. This suggests that immune differences observed in this study were not large enough to initiate mortality differences. It could be interesting to reproduce the same study with a less important stressor than a shaking stress together with one hour of emersion time to see if the differential reaction of the two stocks induce differences of growth in a higher survival context. The fact that $\mathrm{THC}_{60}$ is associated with a better growth rate in the second MFA model and that growth rates in the post stress period and the summer period are correlated consolidates the idea the that the rise of THC is a positive reaction to the acute stress. 
Two hypotheses can be proposed to explain why that summer growth was higher in our farmed

487 abalone than in the wild ones. Firstly, farm abalone may be better adapted to the rearing 488 structures due to unintentional selection, or individuals in this cohort with higher growth 489 performance may have been selected during the early stages of rearing. Secondly, farmed 490 abalone may have had a better recovery from the stress period, as no differences were observed 491 just after the stress. As the growth of wild individuals was close to 0 , it is also possible that they were not able to recover from the stress period in winter and therefore stopped growing. Another

493

494

495

496

497

498

499

500

501

502

503

504

505 physiological status as farm abalone at the beginning of the experiment because the farm abalone were fed in the winter and the availability of suitable algae is likely to be lower in the winter in the wild. 


\section{$\underline{\text { Conclusion }}$}

508 Our study suggests that a domestication process may have occurred in a single generation of 509 rearing in the European abalone $H$. tuberculata. The farm environment seems to have modified 510 the response to different stressors of our farmed stock compared to the wild one. The rise of

511 THC after an acute stress, the return to a lower level of THC after one week of recovery and 512 the return to a basal phagocytosis efficiency level appear to be positive reactions to stressors 513 and these reactions characterised the response of farmed abalone. Interestingly the two stocks responded differentially to shaking and finger contact, but this was not associated with significant differences of later survival or post-stress growth. This suggests that the impact of the farm environment on the biology of our farmed stock did not have a huge impact in its agronomic performances and did not induce rapid economic gains. The effect of a captive environment and husbandry practice on the behaviour and immune response of abalone was unexpected, although this has been previously reported in salmon (Christie et al., 2012).

520

521

522

523

524

525 


\section{$\underline{\text { Acknowledgments }}$}

533 The authors would like to thank the team of France Haliotis, Xavier Lesage, Frederic Laurans,

534

535

536

537

538

539

540

541

542

543

544

545

546

547

550

551

552

553

Mickael Gleeson, Iain McKensy, and Maryvonne Leroux for the provision and care of the animals, and assistance during the experiment. In addition, they would like to thank the LEMAR diving team for collecting wild abalone in difficult winter conditions. Thanks to Mick Keough, who helped with the analysis. This work was conducted in the context of a PhD partially funded by France Haliotis and ANRT (CIFRE N 2014 0643). This work benefited from the support of the European Union (FEAMP) via the program 42 of the FEAMP "innovation in aquaculture" through the "GenOrmeau" project.

\section{$\underline{\text { References }}$}

Allen, V.J., Marsden, I.D., Ragg, N.L.C., Gieseg, S., 2006. The effects of tactile stimulants on feeding, growth, behaviour, and meat quality of cultured Blackfoot abalone, Haliotis iris. Aquaculture 257, 294-308.

Baldwin, J., Elias, J.P., Wells, R.M.G., Donovan, D.A., 2007. Energy metabolism in the tropical abalone, Haliotis asinina Linné: Comparisons with temperate abalone species. J. Exp. Mar. Biol. Ecol. 342, 213-225.

Cenni, F., Parisi, G., Gherardi, F., 2009. Use of space and costs/benefits of locomotion strategies in the abalone, Haliotis tuberculata. Ethol. Ecol. Evol. 21, 15-26.

Cenni, F., Parisi, G., Scapini, F., Gherardi, F., 2010. Sheltering behavior of the abalone, Haliotis tuberculata L., in artificial and natural seawater: The role of calcium. Aquaculture 299, 67-72. 
Cheng, W., Hsiao, I.S., Chen, J.C., 2004a. Effect of ammonia on the immune response of Taiwan abalone Haliotis diversicolor supertexta and its susceptibility to Vibrio parahaemolyticus. Fish Shellfish Immunol. 17, 193-202.

Cheng, W., Hsiao, I.S., Hsu, C.H., Chen, J.C., 2004b. Change in water temperature on the immune response of Taiwan abalone Haliotis diversicolor supertexta and its susceptibility to Vibrio parahaemolyticus. Fish Shellfish Immunol. 17, 235-243.

Cheng, W., Li, C.H., Chen, J.C., 2004c. Effect of dissolved oxygen on the immune response of Haliotis diversicolor supertexta and its susceptibility to Vibrio parahaemolyticus. Aquaculture 232, 103-115.

Cheng, W., Yeh, S.P., Wang, C.S., Chen, J.C., 2002. Osmotic and ionic changes in Taiwan abalone Haliotis diversicolor supertexta at different salinity levels. Aquaculture 203, 349-357. Christie, M.R., Marine, M.L., Fox, S.E., French, R.A., Blouin, M.S., 2016. A single generation of domestication heritably alters the expression of hundreds of genes. Nat. Commun. 7, 6 .

Christie, M.R., Marine, M.L., French, R.A., Waples, R.S., Blouin, M.S., 2012. Effective size of a wild salmonid population is greatly reduced by hatchery supplementation. Heredity 109 , 254-260.

Clavier, J., Richard, O., 1986. Estimation du stock naturel d'ormeaux (Haliotis tuberculata) dans la région de Saint-Malo, Insititution des pêches maritimes p. 11.

Day, R., Dowell, A., Sant, G., Klemke, J., Shaw, C., 1995. Patchy predation: Foraging behaviour of Coscinasterias calamaria and escape responses of Haliotis rubra. Mar. Freshwat. Behav. Physiol. 26, 11-33.

Day, R.W., Quinn, G.P., 1989. Comparisons of treatments after an analysis of variance in ecology Ecol. Monogr. 59, 433-463. 
Dixon, C.D., Day, R.W., Huchette, S.M.H., Shepherd, S.A., 2006. Successful seeding of hatchery-produced juvenile greenlip abalone to restore wild stocks. Fish Res. 78, 179-185. Duchemin, M.B., Auffret, M., Wessel, N., Fortier, M., Morin, Y., Pellerin, J., Fournier, M., 2008. Multiple experimental approaches of immunotoxic effects of mercury chloride in the blue mussel, Mytilus edulis, through in vivo, in tubo and in vitro exposures. Environ. Pollut. 153, 416-423.

Elliott, N.G., 2000. Genetic improvement programmes in abalone: what is the future? Aquac. Res. 31, 51-59.

Forster, G.R., 1962. Observations on the ormer population of Guernsey. Journal of the Marine Biological Association, U.K. 42, 493-498.

Friggens, N.-C., Sauvant, D., Martin, O., 2010. Vers des définitions opérationnelles de la robustesse s'appuyant sur des faits biologiques :1'exemple de la nutrition. Inra Prod. Anim 23, 43-52.

Hansen, S.C., Gosselin, L.A., 2013. Do predators, handling stress or field acclimation periods influence the survivorship of hatchery-reared abalone Haliotis kamtschatkana outplanted into natural habitats? 23, 246-253.

Hansen, S.C., Gosselin, L.A., 2016. Are hatchery-reared abalone naïve of predators? Comparing the behaviours of wild and hatchery-reared northern abalone, Haliotis kamtschatkana (Jonas, 1845). Aquac. Res. 47, 1727-1736.

Hooper, C., Day, R., Slocombe, R., Benkendorff, K., Handlinger, J., 2011a. Effect of movement stress on immune function in farmed Australian abalone (hybrid Haliotis laevigata and Haliotis rubra). Aquaculture 315, 348-354.

Hooper, C., Day, R., Slocombe, R., Benkendorff, K., Handlinger, J., 2011b. Effect of movement stress on immune function in farmed Australian abalone (hybrid Haliotis laevigata and Haliotis rubra). Aquaculture 315, 348. 
Hooper, C., Day, R., Slocombe, R., Benkendorff, K., Handlinger, J., Goulias, J., 2014a.

Effects of severe heat stress on immune function, biochemistry and histopathology in farmed Australian abalone (hybrid Haliotis laevigata x Haliotis rubra). Aquaculture 432, 26-37.

Hooper, C., Day, R., Slocombe, R., Benkendorff, K., Handlinger, J., Gouliasf, J., 2014b.

Effects of severe heat stress on immune function, biochemistry and histopathology in farmed Australian abalone (hybrid Haliotis laevigata $\times$ Haliotis rubra). Aquaculture 432, 26.

Hooper, C., Hardy-Smith, P., Handlinger, J., 2007. Ganglioneuritis causing high mortalities in farmed Australian abalone (Haliotis laevigata and Haliotis rubra). Aust. Vet. J. 85, 188-193. Huchette, S.M.H., Koh, C.S., Day, R.W., 2003. Growth of juvenile blacklip abalone (Haliotis rubra) in aquaculture tanks: effects of density and ammonia. Aquaculture 219, 457-470.

Josse, J., Timmerman, M., Kiers, H.A., 2013. Missing values in multi-level simultaneous component analysis. Chemometr. Intell. Lab. 129, 21-32.

Kojima, H., 1995. Evaluation of abalone stock enhancement through the release of hatcheryreared seeds. Mar. Freshwat. Res. 46, 689-695.

Lachambre, S., Huchette, S., Day, R., Boudry, P., Rio-Cabello, A., Fustec, T., Roussel, S., 2017. Relationships between growth, survival, physiology and behaviour - A multi-criteria approach to Haliotis tuberculata phenotypic traits. Aquaculture 467, 190-197.

Lé, S., Josse, J., Husson, F., 2008. FactoMineR: An R Package for Multivariate Analysis. J. Stat. Softw 25, 18 .

Lorenzen, K., Beveridge, M.C.M., Mangel, M., 2012. Cultured fish: integrative biology and management of domestication and interactions with wild fish. Biol. rev. 87, 639-660.

Malham, S.K., Lacoste, A., Gelebart, F., Cueff, A., Poulet, S.A., 2003. Evidence for a direct link between stress and immunity in the mollusc Haliotis tuberculata. J. exp. zool. Part. A. 295A, 136-144. 
Millot, S., Péan, S., Leguay, S., Vergnet, A., Chatain, B., Bégou, M.-L., 2010. Evaluation of behavioral changes induced by a first step of domestication or selection for growth in the European sea bass (Dicentrarchus labrax): A self-feeding approach under repeated acute stress. Aquaculture 306, 221-217.

Monget, P., Le Bail, P.-Y., 2009. Le phénotypage des animaux : le nouveau défi ? Renc.

Rech. Ruminants 16, 407-409.

Quinn, G., Keough, M., 2002. Experimental Design and Data Analysis for Biologists. Ragg, N.L.C., Taylor, H.H., Behrens, J., 2000. Stress and weight loss associated with handling in the blackfoot abalone, Haliotis iris. J. Shellfish Res. 19, 528-529.

Ragg, N.L.C., Watts, E., 2015. Physiological indicators of stress and morbidity in commercially handled abalone Haliotis iris. J. Shellfish Res. 34, 455-467.

Robinson, N., Smith, B., Cooke, I., Strugnell, J., 2013. A snail's pace: A preliminary analysis of the effects of stress and genetics on movement of Haliotis. Aquaculture 376, 25-35. Shepherd, S.A., and Cannon, J., 1988. Studies on southern Australian abalone (genus Haliotis) X. Food and feeding in juveniles. J. Malac. Soc. Aust. 9, 21-26.

\section{Straus, K.M., Friedman, C.S., 2009. Restoration aquaculture of the pinto abalone (Haliotis} kamtschatkana kamtschatkana Jonas): impacts of rearing method on behaviour, growth and survivorship in the hatchery. Mar. Freshw. Res. 60, 1021-1028.

Taris, N., Batista, F.M., Boudry, P., 2007. Evidence of response to unintentional selection for faster development and inbreeding depression in Crassostrea gigas larvae. Aquaculture Ireland 272, 69-79.

Teletchea, F., Fontaine, P., 2014. Levels of domestication in fish: implications for the sustainable future of aquaculture. Fish. Fish. 15, 181-195. 
650

651

652

653

654

655

656

657

658

659

660

661

662

663

664

665

666

667

668

669

670

671

672

673

674

Travers, M.A., 2008. Interaction de la bactérie Vibrio harveyi avec son hôte, l'ormeau

Haliotis tuberculata : approches physiologiques, cellulaires et moléculaires, Université de Bretagne Occidental.

Travers, M.A., da Silva, P.M., Le Goic, N., Marie, D., Donval, A., Huchette, S., Koken, M.,

Paillard, C., 2008a. Morphologic, cytometric and functional characterisation of abalone

(Haliotis tuberculata) haemocytes. Fish Shellfish Immunol. 24, 400-411.

Travers, M.A., Le Goic, N., Huchette, S., Koken, M., Paillard, C., 2008b. Summer immune depression associated with increased susceptibility of the European abalone, Haliotis tuberculata to Vibrio harveyi infection. Fish Shellfish Immunol. 25, 800-808.

Warton, D.I., Hui, F.K.C., 2011. The arcsine is asinine: the analysis of proportions in ecology. Ecology 92, 3-10.

Table 1: Description of the variables used in this study

\section{Tables:}

Table 2: Behaviour by farmed and wild abalone origin after touching the foot of abalone in a $\underline{\text { standardized manner }(\% \text { of each population. Comparison by Fisher test, NS }=\text { Non significant }}$ $\underline{\text { differences) and a righting test }}$

Table 3: Comparison between wild and farmed abalone origins of the mean of survival and growth rates by ANOVA for length and growth, and Kruskal Wallis test for survival

Table 4: Relationships between the variables and the MFA component (the values mentioned is the $\cos ^{2}$ between the variables and the component) 
Figure 1: Representation of the experimental design at three levels: the global experiment design, a batch of the laboratory period and the detail of shaking and haemolymph procedure

679

Figure 2: The means and standard errors of a) the phagocytosis efficiency in \% (Phago) and b) the THC

681

682

683 in cells. $\mu \mathrm{L}^{-1}(\boldsymbol{T H C})$. Black bars: farmed origin. Grey bars: wild origin. The $\mathrm{X}$ axis shows the time of measurement after the shaking on day 15. T0: just after the shaking, T30: 30 minutes after, T60: 60 minutes after, End: on day 21 at the end of the 3 week stress period. a, b indicate the significance of differences between the times of measurement within each origin. Differences between origins at one time are represented by $*$ when Pvalue $<0,05$ and $\bullet$ when Pvalue $<0,1$.

Figure 3: Multiple factorial phenotype differentiation between wild and farmed abalone ( $n=60)$ : 1) Individual map: wild abalone in gray and farmed abalone in black, Origin (farmed abalone / wild abalone), 2) Quantitative variable factor map: Phago $_{\text {Tend }}=$ phagocytosis efficiency at the end of the stress period, $\boldsymbol{T H C}_{\boldsymbol{T} 6 \mathbf{0}}=\mathrm{THC} 60$ minutes after the shaking, $\boldsymbol{T H} \boldsymbol{C}_{\text {Tend }}=\mathrm{THC}$ at the end of the stress period; SurvRank= survival rank

Figure 4: Multiple factorial phenotype differentiation between wild and farmed abalone, in relation with growth rates: 1) Individual map: wild abalone in gray and farmed abalone in black and the barycentre of each group (W, F) 2) Quantitative variable factor map: $\boldsymbol{P h a g o}_{\text {Tend }}=$ phagocytosis efficiency at the end of the stress period, $\boldsymbol{T H}_{\boldsymbol{T} \boldsymbol{6} \boldsymbol{0}}=\mathrm{THC} 60$ minutes after the shaking, $\boldsymbol{T H} \boldsymbol{C}_{\boldsymbol{T e n d}}=\mathrm{THC}$ at the end of the stress period; $\boldsymbol{G}_{\mathbf{0 - 3}}$ Monthly growth in length in the spring at low density; $\boldsymbol{G}_{3-6}$ Monthly growth in length in the summer at normal density. 
Figure 1 :

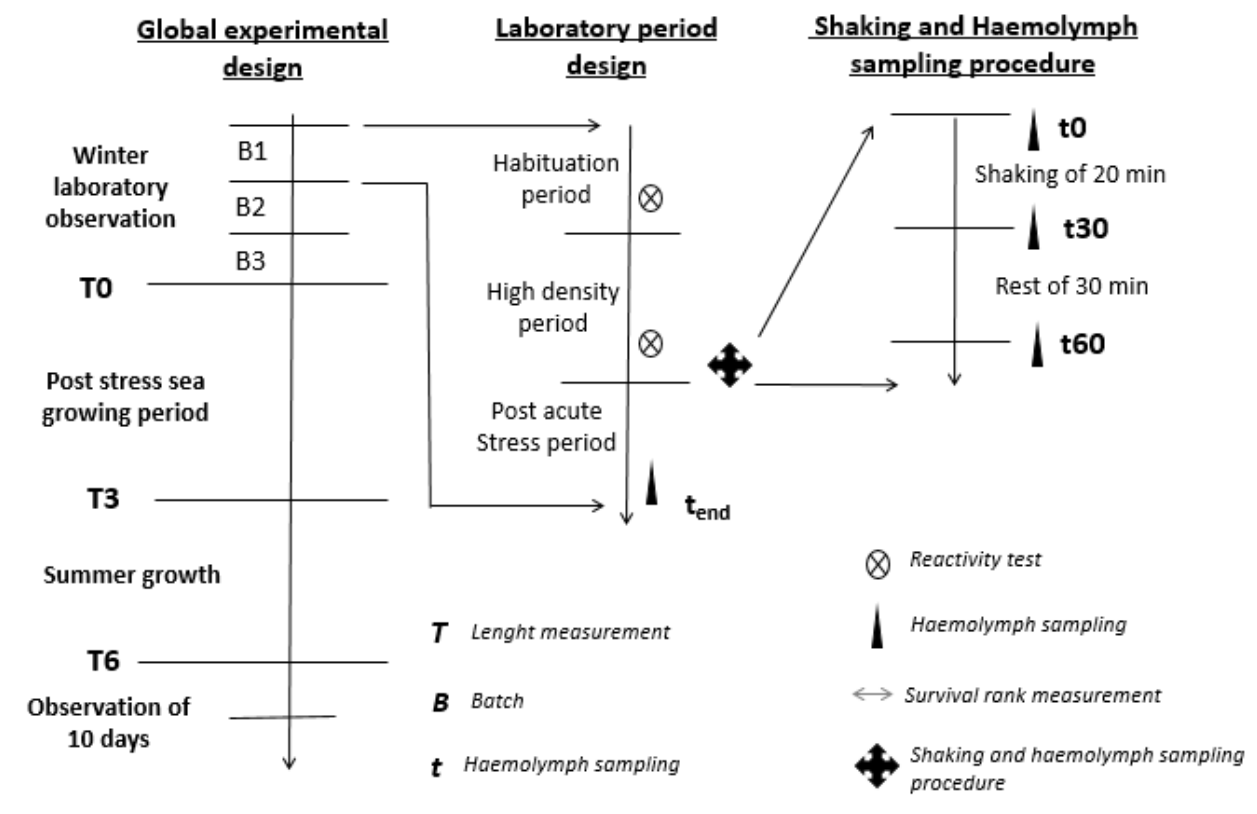


Figure 2:

1

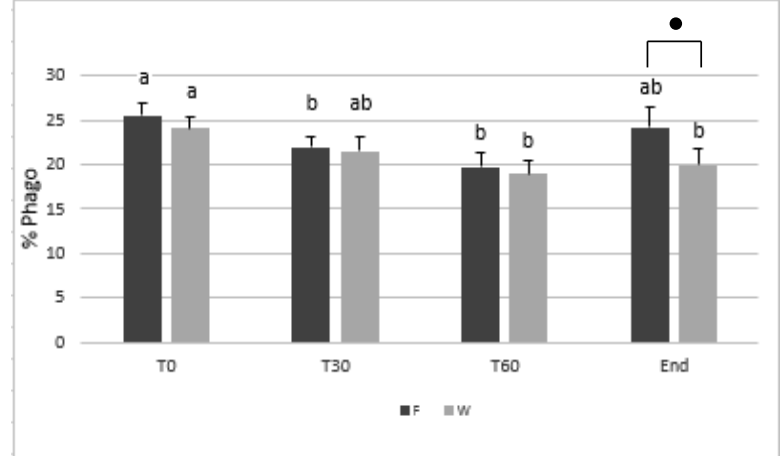

2

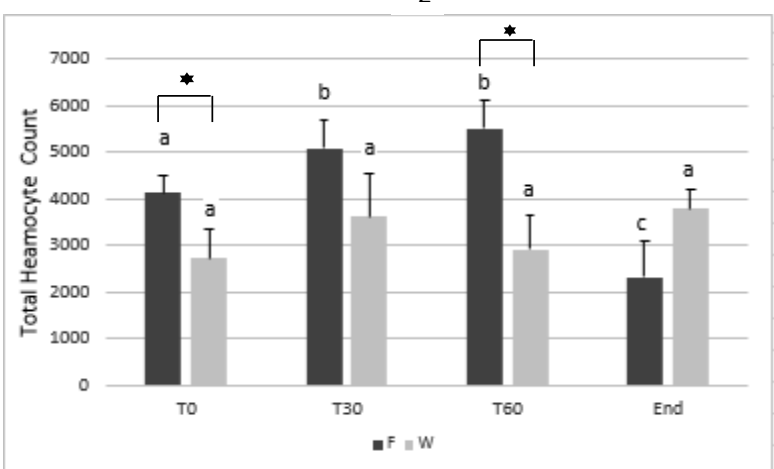


Figure 3 :

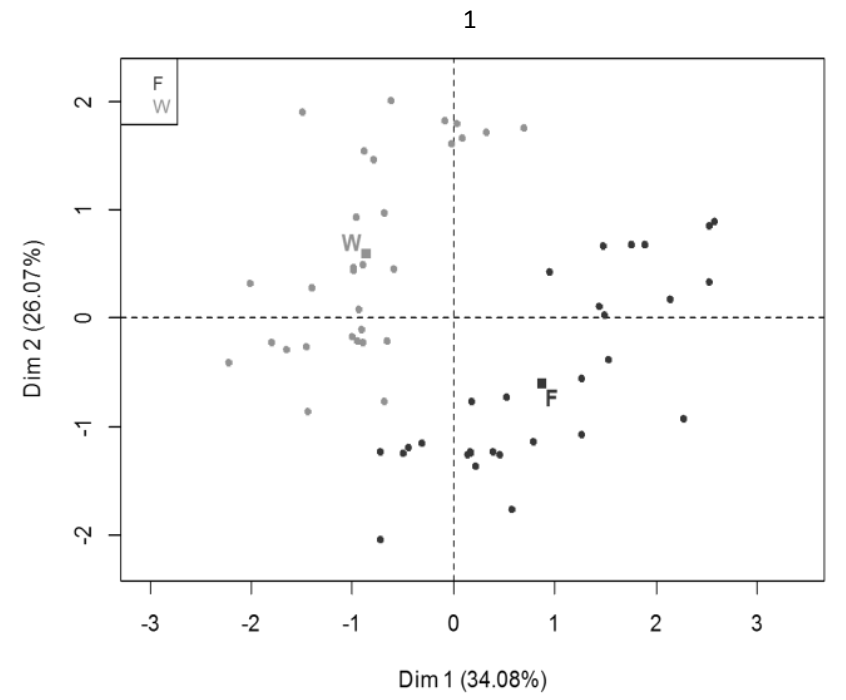

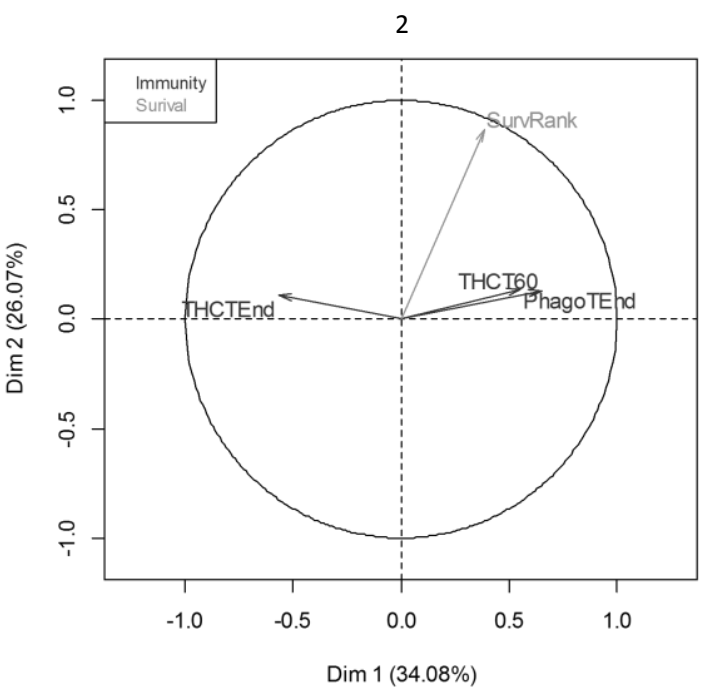


$\underline{\text { Figure } 4}$
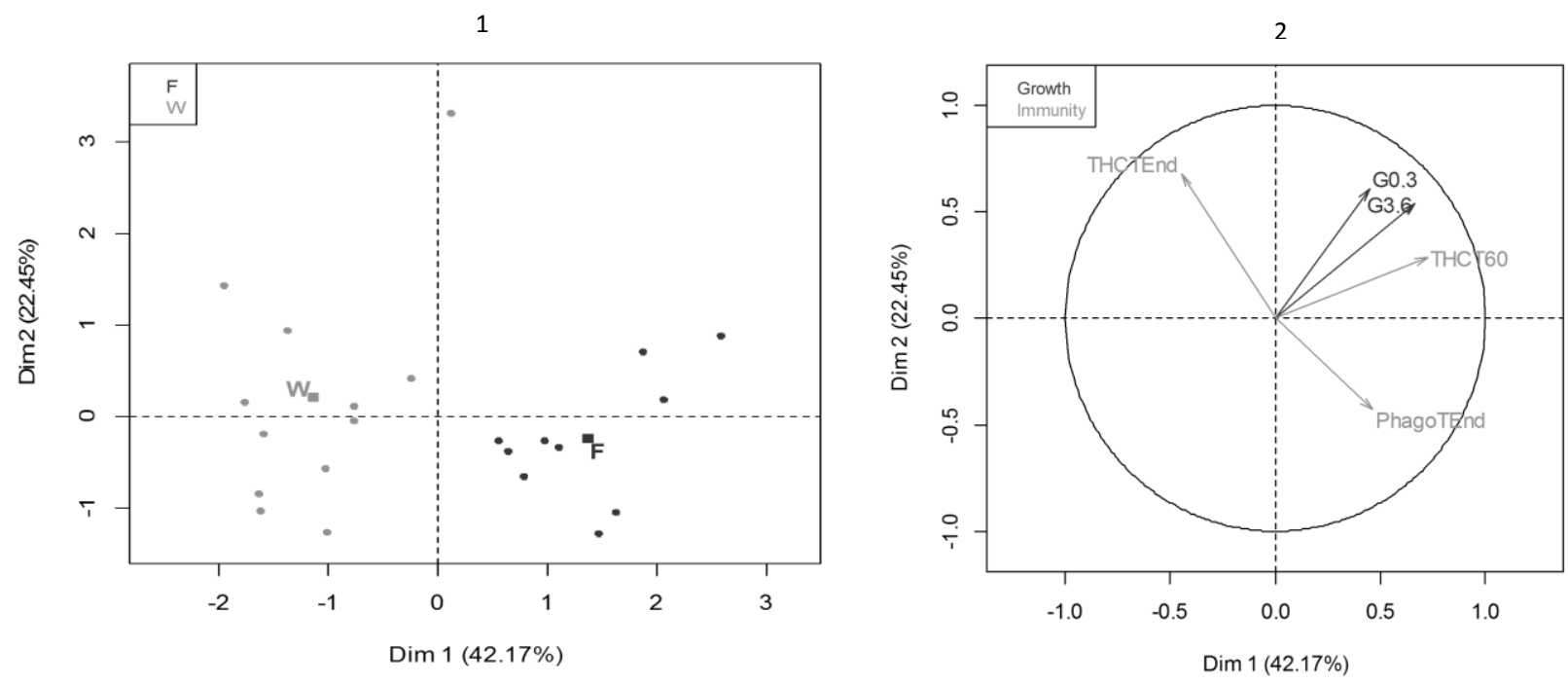
$\underline{\text { Table 1: }}$

\begin{tabular}{|c|c|c|}
\hline $\begin{array}{l}\text { Variables } \\
\text { categories }\end{array}$ & Variables names & Variables definitions \\
\hline \multirow{2}{*}{ Growth } & $G_{0-3}$ & Growth in length between $\mathrm{T} 0$ and $\mathrm{T} 3$, mm.month \\
\hline & $G_{3-6}$ & Growth in length between T3 and T6, mm.month \\
\hline Survival & SurvRank & $\begin{array}{c}\text { Survival Rank with } 5 \text { categories: } 0=\text { Abalone dead during the laboratory period, } \\
1=\text { abalone dead before } \mathrm{T} 3,2=\text { abalone dead between } \mathrm{T} 3 \text { and } \mathrm{T} 6,3=\text { abalone dead } \\
\text { during the } 10 \text { days of summer observations, } 4=\text { abalone alive at the end of the } \\
\text { experiment }\end{array}$ \\
\hline Origin & Origin & Origin of the abalone study: farm abalone labelled F, and wild abalone $\mathrm{W}$ \\
\hline \multirow{7}{*}{ Behaviour } & Hab.RetractT0 & $\begin{array}{l}\% \text { of the population with a retracted foot, on day } 7 \text { of the habituation period } \\
\text { (Hab.RetractT0.O= Abalone with foot retracted, Hab.RetractT0.N=Abalone with } \\
\text { foot relax) }\end{array}$ \\
\hline & Hab.SwivellT1 & $\begin{array}{l}\% \text { of the population that performed a swivelling movement in reaction to finger } \\
\text { contact, on day } 7 \text { of the habituation period }\end{array}$ \\
\hline & Hab.RetractT2 & $\begin{array}{l}\% \text { of the population that retracted the foot after a finger contact, on day } 7 \text { of the } \\
\text { habituation period }\end{array}$ \\
\hline & HighD.RetractT0 & $\%$ of the population with a retracted foot, on day 7 of the high density period \\
\hline & HighD.SwivelT1 & $\begin{array}{l}\% \text { of the population that performed a swivelling movement in reaction to a finger } \\
\text { contact, on day } 7 \text { of the high density period }\end{array}$ \\
\hline & HighD.RetractT2 & $\begin{array}{c}\% \text { of the population that retracted the foot in reaction to a finger contact, on day } 7 \\
\text { of the high density period }\end{array}$ \\
\hline & Righting & The time needed by the abalone to turn itself over when placed upside down \\
\hline \multirow{8}{*}{ Physiology } & $T H C_{T 0}$ & Total haemocyte count before the shaking in in cells/ $\mathrm{yL}^{-1}$ \\
\hline & $T H C_{T 30}$ & Total haemocyte count 30 minutes after the shaking in cells/ $\mathrm{yL}^{-1}$ \\
\hline & $T H C_{T 60}$ & Total haemocyte count 60 minutes after the shaking in cells/ $\mathrm{yL}^{-1}$ \\
\hline & THC ${ }_{\text {TEnd }}$ & Total haemocyte count 6 days after the shaking in cells/ $\mathrm{yL}^{-1}$ \\
\hline & Phago $_{T 0}$ & Phagocytosis efficiency before the shaking \\
\hline & Phago $_{T 30}$ & Phagocytosis efficiency 30 minutes after the shaking \\
\hline & Phagot60 $_{\text {Th }}$ & Phagocytosis efficiency 60 minutes after the shaking \\
\hline & Phago $_{\text {Tend }}$ & Phagocytosis efficiency 6 days after the shaking \\
\hline
\end{tabular}


Table 2:

\begin{tabular}{|c|c|c|c|c|c|}
\hline & $\begin{array}{c}\text { wild } \\
\text { stock }\end{array}$ & $\begin{array}{c}\text { farmed } \\
\text { stock }\end{array}$ & $\begin{array}{l}\text { N(wild, } \\
\text { farmed) }\end{array}$ & Stat-Test & Pvalue \\
\hline \multicolumn{6}{|l|}{ Habituation period } \\
\hline $\begin{array}{l}\text { Hab.RetractT0 (\% of the population } \\
\text { with foot retracted) }\end{array}$ & $60 \%$ & $63 \%$ & 30,30 & 3.8 & NS \\
\hline $\begin{array}{c}\text { Hab.SwivellT1 ( } \% \text { of the population } \\
\text { that swivelled in reaction to a finger } \\
\text { contact) }\end{array}$ & $33 \%$ & $10 \%$ & 30,30 & 5.5 & $\mathrm{P}=0,06$ \\
\hline $\begin{array}{l}\text { Hab. Retract T2 }(\% \text { of the population } \\
\text { that retracted the foot after a finger } \\
\text { contact) }\end{array}$ & $26 \%$ & $10 \%$ & 30,30 & 6.3 & $\mathrm{P}=0,03$ \\
\hline \multicolumn{6}{|l|}{ High density period } \\
\hline $\begin{array}{l}\text { HighD.RetracT0 (\% of the population } \\
\text { with foot retracted) }\end{array}$ & $68 \%$ & $66 \%$ & 28,29 & 0.12 & NS \\
\hline $\begin{array}{c}\text { HighD.SwivelT1 ( } \% \text { of the population } \\
\text { that swivelled in reaction to a finger } \\
\text { contact) }\end{array}$ & $25 \%$ & $3 \%$ & 28,29 & 6.8 & $\mathrm{P}=0,01$ \\
\hline $\begin{array}{l}\text { HighD.RetractT2 }(\% \text { of the } \\
\text { population that retracted their foot after } \\
\text { a finger contact) }\end{array}$ & $21 \%$ & $24 \%$ & 28,29 & 1.08 & NS \\
\hline Righting (Time to right in min) & 1.6 & 1.3 & $25 ; 23$ & 1.8 & NS \\
\hline
\end{tabular}


$\underline{\text { Table } 3}$

\begin{tabular}{|c|c|c|c|c|c|c|}
\hline & wild & farmed & $\begin{array}{l}\text { N(wild, } \\
\text { farmed) }\end{array}$ & $\begin{array}{l}\text { Stat } \\
\text { Test }\end{array}$ & Df & Test \\
\hline $\boldsymbol{L}_{\boldsymbol{T} \boldsymbol{0}}($ Initial length in $\mathrm{mm})$ & $70,1 \pm 1,45$ & $70.0 \pm 1,40$ & 30,30 & 0.19 & $1 ; 58$ & NS \\
\hline SurvivalR & $2.3 \pm 0.26$ & $1.9 \pm 0.23$ & 30,30 & 0.73 & $1: 58$ & NS \\
\hline $\begin{array}{c}\boldsymbol{G}_{0-3} \text { (between T0 and T3, } \\
\text { mm.month) }\end{array}$ & $0.03 \pm 0,09$ & $0.18 \pm 0,09$ & 17,14 & 1.3 & $1 ; 20$ & NS \\
\hline $\begin{array}{c}\boldsymbol{G}_{3-6}(\text { between T0 and T3, } \\
\text { mm.month) }\end{array}$ & $0.07 \pm 0,10$ & $0.36 \pm 0 ; 11$ & 12,10 & 4.6 & $1 ; 20$ & $\mathrm{P}=0,04$ \\
\hline
\end{tabular}


Table 4:

\begin{tabular}{|c|c|c|c|c|c|}
\hline \multicolumn{3}{|c|}{ MFA model 1: } & \multicolumn{3}{|c|}{ MFA model 2} \\
\hline $\begin{array}{c}\text { Variables } \\
\text { name }\end{array}$ & $\begin{array}{c}\text { MFA } \\
\text { component } 1\end{array}$ & $\begin{array}{c}\text { MFA } \\
\text { component } 2\end{array}$ & $\begin{array}{c}\text { Variables } \\
\text { name }\end{array}$ & $\begin{array}{c}\text { MFA } \\
\text { component } 1\end{array}$ & $\begin{array}{c}\text { MFA } \\
\text { component 2 }\end{array}$ \\
\hline Origin & 0.63 & 0.43 & Origin & 0,94 & 0,03 \\
\hline Phago $_{\text {Tend }}$ & 0,30 & 0,02 & Phago $_{\text {Tend }}$ & 0,21 & 0,18 \\
\hline$T H C_{T 60}$ & 0,42 & 0,02 & $T H C_{T 60}$ & 0,53 & 0,08 \\
\hline$T H C_{T E n d}$ & 0,32 & 0,02 & $T H C_{T E n d}$ & 0,20 & 0,46 \\
\hline SurvRank & 0,14 & 0,75 & $\boldsymbol{G}_{0-3}$ & 0,20 & 0,37 \\
\hline & & & $G_{3-6}$ & 0,45 & 0,29 \\
\hline
\end{tabular}

